\title{
Mitología Embera. Principales mitos, características y funciones
}

\section{Embera mythology. Main myths, features and functions}

\section{Antonio María Cardona ${ }^{1}$, Jairo Miguel Guerra Gutiérrez²}

Sueñe y cuéntele a su gente, aunque no le crean, que aqui en la selva hay hombres que no sabemos nada, pero lo soñamos todo, y que el sueño es el camino del conocimiento.

Sakidi, sacerdote Embera, alto río Sinú, Córdoba

Si no existiera una ley de origen, andaríamos ciegos y perdidos en el mundo.

Milton Cabrera, docente Embera, río Chorí, Chocó

\section{Resumen}

El presente texto es un análisis antropológico de los principales mitos emberas, sustentado en la investigación diagnóstica realizada desde inicios del año 2012 en las comunidades indígenas de Jawa (río Chorí), Tandó y Nuqui arriba (río Nuqui) y Yucal (río Panguí), región del golfo de Tribugá, municipio de Nuqui costa pacífica chocoana, reforzada con experiencias de otras investigaciones sobre cosmogonía embera en varias comunidades del Chocó y Córdoba en la década de 1980. La tradición oral, fuente y base del análisis proviene de ancianos, sacerdotes emberas, llamados jaibaná (teólogos y filósofos naturalistas), mayores llamados en algunas comunidades noko, son los caciques principales (jefes naturales tradicionales, remplazados hoy por gobernadores) y algunos docentes bilingües. El análisis de esta mitología muestra la importancia de la misma para el seguimiento de normas sociales y ecológicas y el riesgo actual en que se encuentra este cuerpo cosmológico para la etnia Embera y para la humanidad, en la medida en que se debilita el sistema de socialización de tradiciones a las nuevas generaciones.

Palabras clave: Mitología embera, Mitos, Orden del universo, Universo embera.

\begin{abstract}
His text is an anthropological analysis of the main Embera myths, based on research conducted diagnosed since early 2012 in indigenous communities Jawa (river Chorí), Tando and Nuqui up (river Nuqui) and Yucal (river Pangui), Tribugá Gulf region, municipality of Nuqui Pacific coast Chocoa$n a$, reinforced by experiences of other research on cosmology in various communities Embera Chocó and Córdoba in the early 1980. Oral tradition, source and basis of the analysis comes from old and elderly, Embera priests, calledjaibaná (theologians and natural philosophers), called in some larger communities noko, the principal chiefs (traditional natural leaders, replaced today by governors) and some bilingual teachers. The analysis of this mythology shows the importance of it to monitor social and environmental standards and the current risk found this cosmological body to the Embera
\end{abstract}

1 Antropólogo, Investigador asociado del Instituto de Investigaciones Ambientales del Pacífico (IIAP), Quibdó, Colombia. e-mail: am.cardona@yahoo.es

2 Antropólogo, Asesor de dirección del Instituto de Investigaciones Ambientales del Pacífico (IIAP), Quibdó, Colombia. e-mail: jairoiiap@gmail.com

Recibido: 10 de diciembre de 2013 Aceptado: 29 de marzo de 2013 


\section{Mitología Embera. AM Cardona, JM Guerra}

and humanity, to the extent that the system is weakened socialization traditions to new generations.

Keywords: Embera universe, Embera mythology, Myths, Order of the universo.

\section{Bases conceptuales}

Mitos, leyendasy cuentos. Aunque en el lenguaje común mito y leyenda son sinónimos, en las ciencias humanas no. La antropología diferencia claramente mito de leyenda. Ambas se definen como narraciones extraordinarias y maravillosas de un pueblo, pero los mitos están referidos al origen de las cosas. El mito siempre da cuenta del origen de algo: el universo, el mundo, el hombre, los propios dioses, los elementos fundamentales de la naturaleza (el agua, el fuego, la lluvia, el relámpago, el trueno, etc). En los mitos, los principales protagonistas son los dioses. Las leyendas están referidas a sucesos extraordinarios donde los protagonistas son los semidioses, los seres excepcionales o héroes, especialmente los héroes culturales como los llama la antropología; aquellos extraños o excepcionales hombres capaces de hazañas y epopeyas más allá del olvido. El cuento por el contrario está referido a sucesos de la vida cotidiana y del hombre común, seres muchas veces anónimos, sin nombres, aunque los sucesos sean mágicos, sobrenaturales y extraordinarios, los protagonistas son humanos, animales o entidades sobrenaturales del mundo de los espíritus.

Los antropólogos categorizan los mitos en principales y secundarios. Los mitos principales o primordiales o de origen están referidos a los orígenes del hombre, del Cosmos, de los hechos o fenómenos naturales o humanos más relevantes. Los mitos secundarios dan cuenta del origen de una especie en particular. Un mito de origen, es la creación del hombre embera, un mito secundario el origen del chontaduro, algunos mitos secundarios están entonces en la categoría de leyendas, pero no todas las leyendas son mitos secundarios.

En literatura no hay líneas tan tajantes y una leyenda o un mito, bien podrían ser un cuento. Los actuales emberas del municipio de Nuquí, llaman indistintamente a estos tres tipos de narraciones "chistes" o "cuentos". Los viejos emberas son más rigurosos, para ellos ninguna de esas denominaciones son válidas, ni la de los antropólogos ni la del hombre común. Para ellos son historias. Historias reales que le sucedieron a los humanos ancestrales y le suceden todavía al pueblo embera. Aquí la importancia del mito y la leyenda, son realidades de las cuales no se duda porque el mundo está allí para corroborarlo. Pakoré Wera creó los árboles y los animales y ellos están ahí para testificarlo. Los jai existen, porque cuando una persona se enferma fue un jai achirúa (malo) que se le metió, y la única manera de alivio es sacándolo del cuerpo (sabio principio médico). Las plantas ayudan, pero es la acción mágica del jaibaná la principal arma contra el mal de jai.

Aunque el mundo fue creado por los dioses para bienestar del humano, los mitos son claros que el mundo embera se mueve por las oposiciones y su continua lucha y movimiento lo trunca o lo desarrolla. Existe un jai kachirúa, pero también existe un jai bía (bueno) capaz de combatirlo.

En el plano metafísico, la luz existe porque vino de la oscuridad, la oscuridad también es luz, porque en ella está implícita. Nunca habrá eterna luz, ni eterna oscuridad, la lucha de contrarios produjo el Universo. La lucha de contrarios justifica el mito del eterno retorno, fuimos creados de la tierra y tierra volveremos a ser.

Jaibaná, el protagonista principal de los mitos. La luz será oscuridad y la oscuridad será luz. Mujer u hombre, el jaibaná es el mago de la tribu, el sacerdote, el filósofo, el poeta, el soñador, el vidente (daubara), el cantor, el médico, psicólogo y consejero. El jaibaná es el ser que mediatiza al hombre con lo sagrado, vínculo y puerta al mundo de lo sobrenatural y lo divino. El guerrero del espíritu, que enfrenta a las entidades maléficas, les disputa su poder y lo hace suyo cuando vence, o se retira prudente cuando está ante fuerzas superiores. En muchos casos, ni siquiera es posible el retiro, muere, es el precio que se paga por el conocimiento.

Desde que está en el vientre materno, un jaibaná droma (chamán grande) puede saber si el niño que va a nacer puede ser o no jaibaná; vienen marcados por la naturaleza, no como los seres de Macondo marcados para la muerte, sino para la vida. Tienen más energía que los demás humanos, y el jaibaná lo puede ver, no con estos ojos, sino con los ojos del ver, la conciencia y el entendimiento en estado onírico o de transe.

El camino del conocimiento es el sueño, dice Sakidi, un sabio y chamán del río Sinú.

¿Cuánto dura hacer un doctorado? me preguntó una vez. Sumando los años de primaria, bachillerato, pregrado y doctorado unos 20 años le dije; bueno para ser soñador, daupará, el que ve más allá, experto, se necesitan entre 40 y 60 años. Borraba con su dedo untado de negra jawa los ánimos de "soñador", de quien le insista que le enseñará rápido.

Todo está en uno me decía, las plantas de poder solo ayudan, pueden abrir las primeras puertas de las "dimensiones", pero las puertas son infinitas como infinito es el universo.

Esto nos da una dimensión del largo trabajo jaibanístico entre los emberas; conocen cientos de especies útiles y medicinales, curan a los enfermos con tomas, baños, emplastos, etc., hacen los cantos de jai que duran noches enteras, entran en trance por el canto, ingesta de chicha 


\section{Bioetnia Volumen 10, 2013}

y alcohol fuerte de alambique, "biche" o "chirrínche", la meditación, el susurro de una palma o el constante tintinear de sus finos bastoncillos de canto y poder, labrados primorosamente en maderas finas, que dan un sonido casi metálico, para ver la planta que puede curar al enfermo, para llamar a los "aliados"; jai benefactores que combatan a los malévolos y los expulsen del cuerpo del enfermo. Hacen conjuros, alejan a los malos espíritus, curan la tierra para la buena cosecha, limpian los ríos de fieras y aconsejan a su gente por el camino del buen vivir. Respetan la naturaleza y sus especies y si han de tomar algo de ella para sus necesidades o para las necesidades de los otros, piden permiso a sus dueños. Porque toda especie tiene un dueño, una madre a la que no hay que enfadar o violentar. Los actuales problemas sociales de sus comunidades lo atribuyen al alejamiento del hombre con lo sagrado. A la ambición blanca que enfermó el alma embera, y para la cual no hay cura conocida, sino la voluntad de la nuestra para volver a vivir lo más posible en paz con la naturaleza, pues el hombre siempre es y será un agresor.

Conocen las historias míticas, las transforman con sus propias experiencias oníricas cada vez que las cuentan, pero manteniendo sus arquetipos ancestrales, aunque siendo realistas ya se cuentan muy poco, como me decía un anciano, "a mí nadie viene a preguntarme si conozco una historia, yo me las guardo". ¿Y no le da tristeza? Sí, mucha tristeza, pero yo no puedo obligarlos a que me oigan. Esto se derrumbó. Corta lacónico, escondiendo la palabra.

La mujer protagonista principal invisible. Parece que las pasadas sociedades emberas eran más equitativas con la mujer, su importancia la demuestran claramente los mitos, pero la sociedad embera actual ha virado hacia algunas prácticas de carácter machista; hasta hace poco se practicaba la clitereptomía, extirpación o cercenamiento del clítoris (cortarlo simplemente), principal órgano de placer en la mujer, hoy rotundamente prohibida por las organizaciones. En mitos y leyendas las mujeres están a la sombra. Pero hay mitos que desde esa oscuridad, muestran claramente su protagonismo de género ${ }^{1}$.

Función de los mitos. A nivel social, de la sicología colectiva, todavía los mitos cumplen una función de regulación social e incluso ecológica. Los mitos y leyenda tienen carácter lúdico, recrean y explican el mundo. También son códigos de normas, tabúes y prescripciones y consejos de lo que no se debe hacer o ser. Veamos ejemplos:

Explicativa (del por qué de algo). Para explicar por qué la tortuga chivigí, tiene el caparazón inferior hundido y por qué Amisurrá, el mono cotudo, tiene aplanada la nariz (chata) y solo se le observan las ñatas, se recurre a la

1 En la historia de la Jepá de la laguna de Boroboro, una poderosa chamán salva al protagonista y encierra a la serpiente gigante que lo succiona todo en el fondo de la laguna. leyenda de cuando estos dos personajes se enfrentan en una lid amorosa por la joven venada y se golpean en esas partes.

Ecológica. Creen los emberas que en las pozas profundas habitan seres del mundo de los yambera, los Nusí, peces enormes de fauces voraces, capaces de trozar el tronco de un hombre en dos partes de una sola dentellada. Se cuidan los pescadores de las áreas de nusí, lo que significa un alivio para los peces, sometidos hoy a una absurda sobre explotación del recurso íctico, por pescas nocivas, antiecológicas de negros e indígenas que han realizado en el pasado envenenando las aguas con plantas altamente tóxicas, poniendo en serio peligro las poblaciones de peces. $\mathrm{O}$ la captura de alevinos en época de reproducción, con mallas de toldillos donde se capturan miles, millones de pequeños pececillos que nunca darán nuevas crías.

Tabú, prevenir. Para prevenir el incesto, se le cuenta a los niños, que el sol y la luna eran dos hermanos que se amaban y Karagabí, en castigo los volvió astros y los separó para siempre en el firmamento.

Resaltar virtudes. En un cuento tradicional, tres hombres y dos mujeres se fueron a cazar tigres. Por la noche son rodeados por una manada de tigres hambrientos. Los dos hombres que eran maridos oficiales de las mujeres del grupo, se acobardan y se vuelan corriendo de pánico, dejando solo al compañero y a sus mujeres. El cazador después de una intrépida noche de combate con los tigre logra matar a muchos y poner a salvo las mujeres, a la llegada a la aldea ellas públicamente abandonan a sus cobardes maridos y las dos se brindan y se convierten en mujeres oficiales del valeroso. Recompensa al valor.

Educativa, ejemplarizante. Imamá, el tigre, se da ínfulas de ser el más poderoso de la selva e impone el terror con los más débiles. Camina siempre gruñendo y con la cabeza alzada, creyéndose dueño del orbe. Kuriva, el humilde y astuto ñeque o guatín, decide darle su merecido al que se cree dueño del mundo, oponiendo inteligencia a fuerza y gruñidos. Astutamente engaña a tigre en varias lides, como el hacerle comer sus propios hijos sin que se dé cuenta de ello, o burlarlo en un baile ante todos los presentes, o incluso, hacerle golpear con su manaza de tigre sus propias guevas. Los tigres siempre son de papel, dice el proverbio chino. Leyenda contra la "importancia personal". Enfermedad psicológica de todos los humanos.

\section{Metodología}

La metodología para obtener esta información está un poco lejos de la academia y la antropología clásica. Notas rápidas de campo y la fotografía como registro etnográfico. El método ha sido el método embera, aprender las historias, escribirlas en la memoria, y luego en el papel. Las recopilaciones se realizan en rumbas al calor de la chicha y el licor, 


\section{Mitología Embera. AM Cardona, JM Guerra}

de tardes solariegas y largos caminos; travesías por la selva en lentas canoas a impulsos de palanca o de las corrientes, y para olvidar el tiempo del viaje que parece detenido y la premura por llegar; de las bocas de los bogas brotan las leyendas, las creencias, las historias de vida, porque el embera verdaderamente habla cuando no se le pregunta. De los pescadores y cazadores en los descansos de las jornadas de caza y pesca en las quebradas, sentados sobre las piedras a la umbría del follaje mientras las mujeres cocinan los peces en rústicas e improvisadas barbacoas. Las recopilaciones de "cuénteme una historia antigua", grabadora y libreta en mano, no tienen la sabrosura del momento de relajo. El narrador se frunce, se pone nervioso, incómodo, olvida fácilmente aspectos, incluso partes de la historia, por lo que este agresivo método viene siendo superado. Ganarse la confianza del interlocutor es el secreto y para eso se necesita tiempo y convivencia. Las investigaciones de 3 o 4 días no sirven al antropólogo.

Algunas de las historias reseñadas en 2012 fueron posibles porque han sido recogidas en sus propios espacios y tiempos por investigadores comunitarios emberas que se están formando como tales con la investigación que actualmente se realiza.

Las historias contadas por los emberas omiten lo tácito de su cultura, pues todos la conocen, la viven; se amplían dándole ese contexto faltante para el lector no indígena. Se hacen las conexiones pertinentes, cuando se obtienen de los mismos relatos en otros informantes. El objetivo es encontrar el hilo ancestral para tejer la colcha de retazos que actualmente es la zaga embera. Los antropólogos no son otra cosa que traductores de cultura.

\section{Mitos principales}

Origen del origen. Al principio no había nada. Ni dioses ni mundos ni animales ni hombres. Al principio no había nada. Soledad, oscuridad y vacío. El misterio. Lo que no se puede conocer. Pero algo... que es más atrás de la memoria, del pensamiento y la palabra, deseaba. Había intención de ser. Intención que era de colores y de música celeste. Lo primero era la Nada y al mismo instante fue una inmensa Luz más grande y más fuerte y luminosa que todas las estrellas que vemos y no vemos en el firmamento; era Jai naciendo, formándose, haciéndose a sí mismo, era Ankoré generándose, haciéndose él mismo, y de ese mismo torbellino de ser, salió, se generó Tachi-nave, la primera diosa y mujer, la primera sabia y chamán, la que iluminó a su marido para que creara al hombre y le indicara cómo hacerlo. Después todo fue calma y movimiento y de lo insondable, incognoscible, inconcebible brotó la memoria, el pensamiento y la palabra. Dayi Ankoré no tiene forma porque tiene todas las formas, es hombre y Padre de todo lo existente, al igual que los es Tachi-nave, mujer, Madre principal de todo lo existente. Ellos son lo femenino, lo masculino y lo asexuado. Eran nuevecitos porque tenían toda la vejez del Universo. Dayi-Ankoré lanzó un escupitajo, el agua primera, y de allí salió, se generó Karagabí, el del cuerpo resplandeciente como luz; destellos dorados $\mathrm{y}$ vestido de filigrana, y en el mismo instante, al mismo tiempo salió, se generó Pakoré wera, la hermosa núbil pintada de jawa y vistosos collares de arco iris, la sabia anciana de cabello negro y largo que le arrastra, y allí en el mismo punto, al mismo tiempo y de la misma saliva, salió y se generó también Tutruika, el dios oscuro, que regirá un mundo de hombres grises, que no tienen boca ni tienen culo y son inmortales ${ }^{2}$.

Ley de Origen. Dayi-Ankoré, nuestro padre, tuvo tres hijos, que son también tres dioses y también nuestros tres primeros hermanos: Karagabi, Tutruika y Pakoré wera. Los tres son los sabios primeros, los primeros jaibaná. Fueron designados por Dayi-Ankoré para que crearan los cinco mundos que existen. Karagabí creó el mundo de los hombres, a Papá Egoró, la Madre tierra y Nentre el mundo azul de los dioses, donde estos se retirarán después de haber creado y ordenado el Universo. Tutruika creó el mundo de los inmortales, los sin culo, llamado Armukurá. Pakoréwera, creó la Naturaleza, los animales y las plantas, el mundo de todo lo vivo. Ella es la sabedora primera de las plantas medicinales. También creó el mundo de los Yambera; el mundo de los jai, de los espíritus; entidades malévolas y benévolas que pueden afectar al hombre. Dayi-Ankoré, Dios principal agradeció a sus hijos el haber creado los mundos, pero aún no estaba satisfecho, sentía que algo faltaba. $\mathrm{Su}$ mujer le sugirió, por qué no creaba a alguien para que pudiera administrar y gozar de lo creado. Él acogió el consejo y decidió hacer al hombre para que habitara la Madre tierra que estaba sin goce y sin administración.

Creación del hombre ${ }^{3}$. Ankoré empezó a tallar un muñeco con figura humana en palo de oquendo; quería que el hombre fuera fino, que durara siempre, que fuera inmortal. Ensimismado estaba en su labor, cuando el duro oquendo hizo resbalar la hoja cortante y Ankoré se hirió en un dedo, ya el hombre estaba casi terminado. Molesto

2 En la mitología del Sinú, Tutruika no es hermano de Karagabi, Tutruika es un dios que se hace solo y disputa con él, en fuerza, astucia, resistencia e inteligencia. Nadie vence a nadie y hacen pacto de no agresión e intercambian sabidurías. 3 Este relato referente a los hijos de Ankoré fue recogido por Baltazar Mecha, líder y etnolingüista embera y cursado escrito a todas las escuelas del Chocó, tuve la oportunidad de leerlo en Tandó y oírlo a viva voz en boca de Miltón Cabrera profesor en la comunidad de Ja Jawa hace algunos días. Pero en los relatos de Baltazar y Milton, Tachi-nave no aparece con nombre específico, se habla solo de Ankoré y que su mujer "le sugirió la creación del hombre". 


\section{Bioetnia Volumen 10, 2013}

dejó su labor inconclusa. Es por esto, que el hombre no es completo ni tampoco inmortal.

Nuevamente Tachi-nave su mujer, le sugirió, hazlo de otro material que sea más blando, más dúctil. Ankoré se fue a la playa del primer río, cogió tierra y la mezcló con agua y modeló dos muñecos con forma humana y con su aliento les infundió vida, apareció la primera pareja humana, hombre y mujer nacieron al mismo tiempo, con sus igualdades y sus diferencias; donde uno, no puede estar sin el otro, después hizo varios muñecos y de la misma manera les infundió vida y así nació la muchedumbre. Es por eso que cuando morimos nos volvemos tierra, volvemos a ser lo que antes éramos.

Los dioses ordenan el mundo. Al inicio del mundo los animales eran como los hombres y los humanos podían hablar con ellos. Pakoré wera, el espíritu de la naturaleza dio los elementos esenciales de la vida de los hombres a los animales para que los custodiaran y los administraran bien, bajo el principio de igualdad y oportunidad para todos, a nadie se les podía negar. Genserá, fue custodia del agua. Jimo del fuego y Kumbarrá de las semillas.

Cuando los hombres agotaban sus elementos acudían a los custodios para que le suministraran más. Pero los hombres no hicieron buen uso de los elementos. Negaron el agua a una anciana que tenía sed. No cuidaban ni sembraban las semillas, otros mezquinaron el fuego y no les importó que los otros comieran crudo los alimentos o titiritaran de frío. Los animales custodios procedieron drásticamente, violando la ley, negaron. Genzerá escondió el agua en la comba de un jenené gigante. Jimo escondió el fuego en su madriguera debajo de la tierra donde tenía su tambo. Kumbarrá escondió también las semillas y por mucho que le rogaban los hombres, no les daba el secreto de cómo cultivar.

En ese tiempo los hombres no conocían la hermana Muerte, sólo conocían la hermana Vida; porque la Vida y la Muerte son dos opuestas hermanas gemelas, y donde está una, muy cerca está la otra. Son inseparables. Nadie todavía había subido a horcajadas sobre Ankosotor, el golero blanco para viajar a Bajá, el mundo donde van los muertos. Los hombres empezaron a morir. Contaron de la desaparición de los elementos esenciales para la vida y la rotunda negativa de los custodios a los dioses. Los dioses intervinieron, y cada solución para devolver a los hombres los elementos vitales, es una larga leyenda. A genserá la volvieron hormiga negra, y del árbol sagrado del agua brotó el mar, los ríos, ciénagas, lagunas y demás fuentes de agua; a Jimo lo volvieron lagarto y los hombres gozaron del fuego y a kumbarrá, pájaro mochilero u oropéndola, y los humanos conocieron el arte de la agricultura.

Edades humanas. Fracaso y nuevas generaciones. La primera generación de hombres embera fracasan y los dioses los convierten en animales. Los dioses crean una segunda generación de hombres que también fracasan, se vuelven promiscuos y no acatan ninguna regla sexual. Los dioses los ahogan en grandes ollas de barro. Karagabí decide probar nuevamente y crea la tercera generación que sucumbe con el conquistador español y la cuarta, se genera de los pocos supervivientes y son los actuales emberas de Colombia, que están repartidos en muchas partes de la geografía nacional, pero la mayor población se concentra en el Chocó, su territorio ancestral.

De su saliva, Karagabi crea una pareja humana. Da a la mujer una totumita de oro y al hombre una gota de agua, para que la coloque cuidadosamente en la totuma de la mujer, ella debe voltearla con cuidado sobre la tierra, el hombre la deposita, pero ella nerviosa y asombrada por los destellos dorados de su tutumita de oro, y curiosa por ver qué pasaba con la gota de agua, la mueve bruscamente y la gota originaria se fragmenta y cuando voltea la totuma sobre la tierra, muchas gotitas menudas quedan por fuera de la totuma. Cuando levantó la totuma salieron muchos hombrecitos que fueron creciendo con el viento, y es la tercera generación de los emberas. Los de fuera de la totuma fueron los demás grupos humanos existentes. Los que más cerca quedaron de la totuma, fueron los Tule, que ellos llamaron Jurá (enemigos), porque rabiosos por no quedar debajo de la totuma, flecharan al Dios y se enemistaron con los emberas. Durante mucho tiempo los tules o Cunas fueron enemigos acérrimos de los emberas, actualmente eso es pasado, hoy luchan hombro a hombro por sus derechos y su cultura. El que más lejos quedó de la totuma fue el hombre blanco, por eso es tan desprendido y alejado del alma de las cosas. Esta parte de la zaga es la más oscura y fragmentada entre los actuales emberas.

Los dioses se retiran. Después de ordenados los mundos, creadas las diferentes generaciones de hombres, los dioses principales se retiran a Nentre el mundo azul. Tachi-nave, Ankoré, Tutruika, Karagabi y Dobeiba, semidiosa de las artes y los oficios, diosa de la lluvia y de los vientos, hija de Karagabí con una mortal, desconocida hoy por las comunidades del Pacífico, no volverán a intervenir en la vida de los hombres. Cualquier acción estará mediatizada por los que quedan en los mundos, Pakoré wera, Antomiá, las entidades de los yamberas, especialmente los jai. El hombre queda a libre albedrío, pues en la punta de la nariz está su suerte y en la punta de sus pies su destino. Ellos verán o andarán ciegos. Es por esto que el embera no adora a los dioses, no tiene cultos específicos hacia ellos, ni levanta altares o recintos para su veneración. Solo en los sueños los dioses pueden tener alguna manifestación.

\section{A manera de análisis}

Ankoré es el Jai primero y todo es una manifestación 


\section{Mitología Embera. AM Cardona, JM Guerra}

de él. Todo tiene jai: la piedra, el viento, el río, la estrella, los animales, las plantas, el hombre. Es por esto que el hombre puede comunicarse con un animal, con una planta, a través de sus jais, de jai a jai, el lenguaje cifrado de las esencias, de las energías, de los espíritus. La mitología embera presenta un buen número de deidades que varían según los informantes y sus grados de aculturación, pero que mantienen un hilo conductor que permite afirmar el carácter panteísta de su cosmovisión, igualmente son deidades ligadas a la existencia, al día de individuos y comunidades y a las dinámicas naturales por lo que igualmente es posible calificarla de animista y naturista.

Karagabi, virtud de bondad, sabio por naturaleza que tiene su morada allá arriba sobre nuestras cabezas, creó los nueve mundos principales, divididos en los cuatro mundo de arriba, los cuatro mundo de abajo y el del centro que es la tierra, este lo reservó para que tuviera todos los colores, poniendo en él la corona del arco iris como testigo de sabiduría (Cardona 2013).

La zaga embera es larga y extensa y varía de región a región, incluso de comunidad a comunidad, pero los arquetipos míticos y legendarios se mantienen. Una larga historia que se compone de muchas historias completas en sí mismas, pero que son solo parte, capítulos de la gran historia mítica del pueblo embera. En las actuales comunidades de investigación Karagabí y Tutruika, tienen poco peso, si bien se les conoce, algunos llegan a afirmar que Karagabi es un dios de lo katios. Los duros siguen siendo: Ankoré y especialmente Pakoré wera.

Los mitos y leyendas más populares y vivos son: origen del hombre, las historias de Jinú-Potó-Warra, las de Jé, o Jepá, la serpiente gigante, las historias de Ventura, un héroe cultural del alto Baudó (para algunas comunidades), las cientos de historias con los extraños seres del mundo de los Yamberas ${ }^{4}$, nusi, aribada, guangano, madres de agua y jais kachirúas, entre los principales. Están regidos por Antomiá o Antumiá para otros, que vive con su Antomiá wera, más poderosa que él. Con la influencia cristiana ha tomado la categoría de diablo, señor del mal. Pero en las leyendas ancestrales, Antomiá no es bueno ni es malo, sencillamente rige el bien y el mal, a él debe aliarse el jaibaná para obtener jais para sus labores mágicas y de curación. Si fuera malo no se los daría para curar, es el hombre el que decide y dispone entre el bien y el mal y no Antomiá. Entre los embera del río Sinú Antomiá se les aparece a los hombres en la forma de un niño tierno, hombre o mujer,

$4 \quad$ Los yamberas, tienen el poder de transformarse en lo que ellos deseen: en seres diminutos, gigantes, humanos normales para engañar a los hombres y hacer sus fechorías, pueden adoptar la forma de grotescos monstruos generalmente con forma de animal feroz, pero combinando partes de estos. sentado entre las aguas jugueteando con los peces; una figura bastante alejada del ser rojo, cuernos, rabo y pezuña de cerdo o macho cabrío del cristianismo. Es más, para los antiguos, Antomíá, es el espíritu del río.

Respecto al rol de género, los mitos primordiales demuestran su importancia en todos los aspectos de la vida social como depositarias y trasmisoras de la cultura ${ }^{5}$, pero en la actualidad hay pocas mujeres en posiciones de gobierno, de reconocimiento oficial como chamanas, tongueras o pildeceras (que toman pildé y tonga, plantas enteógenas, de poder) aunque es de reconocerse el esfuerzo de los actuales porque las mujeres participen en roles de poder. Ahora hay más niñas emberas en la escolaridad que en otros años, algunas ocupan cargo en los cabildos indígenas.

Desgraciadamente los sabios emberas están muriendo día tras día, y las nuevas generaciones no están recibiendo su legado. Las teorías de Einstein (1961) como las de Hawking (1988) seguirán en discusión porque están escritas. La Cosmogonía embera hoy notablemente fragmentada está en la cabeza de algunos viejos, ellos son libros vivos y cuando mueran no los podemos abrir jamás; en literatura se dice que no es tan importante el autor con tal de que quede el poema. Con el ávido deseo de cambio hacia la modernidad de las actuales generaciones emberas muy pronto no habrá un relato para escuchar.

En síntesis, los mitos y leyendas son formas de pensamiento colectivo que tratan de oponer la entropía al movimiento dialéctico del Cosmos. En ese desorden ordenado que es el Universo, el embera antepone la entropía misma como acción metafísica, para no sucumbir a la oscuridad y al vacío, antepone el orden desordenado del universo. Lo que Frazer (1944) en su obra La Rama dorada llamaba lo parasimpático, el viejo principio homeopático, que con lo mismo que uno se enferma, se cura. Lo mejor para quitar las manchas del plátano, es el mismo plátano. Pero las historias ancestrales se han ido hibridando con los mitos del cristianismo, desde que curas y monjas aparecieron armando escuelas e internados. Ellos han sido el elemento más nocivo de la aculturación de los embera y la contaminación de sus mitos y creencias. Actualmente el permanente contacto con la sociedad occidental da fuertes pisadas de animal grande por todos los territorios indios y más por la mente embera. Ya Pakoré wera, el espíritu femenino de la selva va siendo remplazado por San Pedro y todo el fetichismo cristiano. El mito de Cristo pronto borrará a Ankoré, a menos que los actuales embera lo vuelvan a pintar en el alma con la jawa de la memoria.

\footnotetext{
Algunos chamanes cuentan que en el pasado, cuando las mujeres podían transitar solas la selva. Existían las tachi-naves, mujeres sagradas, que recorrían la manigua recogiendo y contandolas historias en todas las comarcas.
} 


\section{Bioetnia Volumen 10, 2013}

\section{Fuentes: La tradición oral y la memoria Informantes Emberas}

\section{Comunidad de Jawa}

José Morales, investigador comunitario

Leovigildo Kunampia, cabildo mayor

Miltón Cabrera, docente

Edgar Sanapí Tripikai, cazador

\section{Comunidad de Nuquí arriba-Tandó}

Armando Hanipe Cabrera, investigador comunitario

María Elia Cabrera, secretaria Cabildo

Juvenal Cabrera, gobernador Tandó

\section{Comunidad de Panguí-Yucal}

Francisco Quiro (Célimo), investigador comunitario

Fátima Cabrera, agricultora

\section{Literatura citada}

Cardona A. 2013. Leyendas Embera. Los guerreros de las cuatro edades. Montería. Inédito.

Frazer J. 1944. La Rama Dorada. Magia y religión. México, DF, Buenos Aires: Fondo de Cultura Económica.

Einstein A. 1961. Relativity. The special and general theory. New York: Crown Publishers.

Hawking S. 1988. A brief history of time. New York: Bantam Books. 